\title{
EL CAMINO DE LA TEORÍA PURA DEL DERECHO* LA OBRA DE KELSEN EN EL CONTEXTO DE LA FILOSOFÍA DEL DERECHO DEL SIGLO XIX Y DEL NEOKANTISMO
}

\author{
"The path to the Pure Theory of Law" \\ Kelsen's work in the context of the $19^{\text {th }}$-century jurisprudence and of \\ neo-kantianism.
}

Javier Wilenmann von Bernath ${ }^{* *}$

\begin{abstract}
Resumen: El artículo presenta una descripción de la influencia de la filosofía del derecho del siglo XIX y de la filosofía neokantiana en la obra de Hans Kelsen. Ambas corrientes de discusión son así presentadas como constitutivas del contexto de sentido de su teoría del derecho. En este contexto, la obra de Kelsen se deja entender correctamente como radicalización de sus principales hallazgos en la conformación de una teoría del derecho desligada de asunciones metafísicas problemáticas y no, en cambio, como una obra revolucionaria en el desarrollo del así llamado positivismo jurídico.
\end{abstract}

Palabras clave: teoría del derecho - filosofía del derecho - neokantismo - validez norma.

\begin{abstract}
The paper describes the influence of the 19th century philosophy of law and of neo-kantianism in Hans Kelsen's work. Both constitute therefore the context in which Kelsen's theory is to be understood. Regarding this context, Kelsen's work can be read as a radicalization of the ideas of both movements in the development of a theory of law untied from problematic metaphysical assumptions rather than as a revolutionary contribution to the development of legal positivism.
\end{abstract}

Keywords: theory of law - philosophy of law - neo-kantianism - validity - norm.

\section{Introducción}

Las grandes obras, aquellas que aparecen como definitorias de un proyecto colectivo cultural o científico, tienden a generar el efecto de nublar su contexto. Esto es particularmente cierto cuando la gran obra trasciende el área de influencia cultural del contexto en el que ella tiene lugar: mientras en su propia área cultural

\footnotetext{
${ }^{*}$ El presente artículo se benefició enormemente de una discusión sobre un borrador de este en el Seminario Académico de la Facultad de Derecho de la Universidad Adolfo Ibáñez. Agradezco una enormidad la invitación a sus organizadores, Constanza Salgado, Francisco Saffie y Adrián Schopf. Reconozco asimismo los valiosos comentarios efectuados por Constanza Salgado a un borrador posterior del artículo.

** Profesor de la Facultad de Derecho de la Universidad Adolfo Ibáñez. LLM Universität Regensburg. Doctor Albert Ludwigs Universität Freiburg. Becario DAAD. Correo electrónico, jwilenmann@yahoo.com
}

Este artículo fue recibido el 8 de octubre de 2013, siendo aprobada su publicación el 10 de mayo de 2014. 
Wilenmann - El camino de la teoría pura del derecho...

el contexto de la gran obra va a seguir siendo, cuando no inmediatamente visible, al menos siempre accesible, sus lectores en otros espacios culturales van a encontrarse casi necesariamente cegados por completo al contexto. Allí, la gran obra no solo va a provocar su efecto natural de aparecer como autogenerada y autosuficiente, sino que el contexto además va a ser difícilmente accesible para quien quiera superar la ilusión.

Un buen ejemplo de este fenómeno puede encontrarse en la recepción de la obra de Hans Kelsen, ante todo de su escrito más famoso, la Teoría Pura del Derecho, fuera del mundo de habla alemana y, en particular, entre nosotros. La Teoría Pura del Derecho tiende a ser presentada como obra revolucionaria en el largo proyecto positivista de conceptualización teórica del derecho; vista de esta forma, la obra ciertamente participaría de un proceso y tendría ancestros, los cuales ya por nombre debieran ser asociados al positivismo legalista, a la teoría de los imperativos y a otros proyectos similares, pero habría al mismo tiempo redefinido ese proyecto. ${ }^{1}$

Esta comprensión es, sin embargo, ciega al contexto dado por el espacio de discusión del que ella forma parte. La obra de Hans Kelsen, al igual que otros aportes cruciales surgidos hacia principios del siglo XX, puede representarse ante todo como continuación de tres proyectos que le anteceden. El primero es el más evidente y, por ello, el menos interesante para nuestros efectos: el proyecto de adaptación de la ciencia del derecho a estándares modernos de cientificidad. ${ }^{2}$ En segundo lugar, se trata del proceso de recepción y desarrollo de la tradición de teorización abstracta del derecho pese a su creciente positivación; ${ }^{3}$ o, explicado en simples conceptos ambiguos pero elocuentes, en el proceso de disección de la filosofía del derecho legado por la tradición del derecho natural en distintas disciplinas - por ejemplo, teoría de la ley o del método jurídico (posteriormente teoría de la argumentación jurídica), teoría del derecho, filosofía del derecho y ética jurídica-. En tercer lugar, la obra de Kelsen participa de un esfuerzo de categorización de fenómenos sociales dominante en general en la cultura académica europea de fines del siglo XIX y principios del siglo XX, el que tiende a designarse bajo la reducción del proyecto al nombre de "neokantismo". En el caso de Kelsen, se trata ante todo de la pretensión de poder comprender bajo su propia lógica (bien podría decirse: bajo sus propias categorías metodológicas) al Estado y

\footnotetext{
${ }^{1}$ El que no solo existe diferencia sino verdadera oposición entre el positivismo anglosajón ligado a la teoría de los imperativos y la teoría del derecho continental surgida del neokantismo, es algo trivialmente conocido. Véase, por ejemplo, DrEIER (1975), pp. 8-9 y 11-13. Pese a ello, fuera del análisis histórico de ambas corrientes, ello tiende a ser desconocido por la agrupación general bajo el concepto excesivamente extenso de "positivismo jurídico".

2 Así también, con ulteriores referencias, PAULSON (2002), pp. 228-230. En Kelsen, basta revisar su declaración explícita al inicio de la Teoría Pura del Derecho (KELSEN (1960), p. 1).

${ }^{3}$ En lo que sigue se utiliza el concepto "positivación" y sus derivados ("positivado" y "positivar") como expresiones de un proceso de reducción del derecho al derecho reconocible por mecanismos formales. Prefiero prescindir de la palabra "positivización" por ser este vinculable a una forma de reconstrucción teórica del derecho, el positivismo jurídico.
} 
al derecho a partir de una peculiar adaptación de una distinción categorial, a saber, entre ser y deber (ser), la que se ve fundada en aquello que Kelsen denominaba "teoría del conocimiento jurídico" y que sirve de sustento general a su obra.

Como intentaré mostrar en este artículo, la pretensión neokantiana de explicitación de lógica interna define el proyecto de Kelsen y es, por lo mismo, de alguna forma perceptible sin más -es decir, sin necesidad de entender la discusión con el neokantismo- en sus escritos maduros. En otras palabras: el efecto de generación de la ilusión de la autosuficiencia propio de la gran obra no es solo un vicio, sino que es a la vez una de las virtudes que lo define. Esto quiere decir: parte importante del interés de la obra de Kelsen es perceptible leyendo la Teoría Pura del Derecho y sin necesidad de hacer referencia a su contexto de discusión. Aún más: el proyecto que supone la obra puede ser evaluado sin dar cuenta de sus orígenes, ya que el contenido mismo de la Teoría Pura del Derecho es revelador del proyecto. En esto puede ser considerado irrelevante que el proyecto sea equivalente a proyectos paralelos en otras áreas en el mismo espacio cultural: si el proyecto es plausible en la cuestión del tratamiento teórico del derecho, es algo que puede ser analizado al menos parcialmente con independencia de la suerte de movimientos relacionados. La revisión del contexto sirve solo para alejar asunciones ingenuas respecto del carácter revolucionario de la obra, pero solo para ello. En cambio, su sustento, la cuestión metafísica de los conceptos de validez y de normas -la teoría del conocimiento jurídico-, no se explica correctamente sin revisión de ese contexto. Algo similar sucede con la cuestión del compromiso con el derecho positivo: este define su obra, pero la forma que toma ese compromiso se entiende mejor a la luz de la evolución de la tradición de filosofía del derecho que le antecede.

El presente artículo tiene de esta forma una doble pretensión. Por una parte, su pretensión más simple es introductoria. Al lector de Kelsen puede serle útil conocer la tradición en la que este se inserta en el tratamiento teórico del derecho. Situar a Kelsen en un lugar en la historia del pensamiento teórico sobre el derecho no tiene de esta forma pretensiones hermenéuticas mayores respecto de la comprensión de la obra en sí, pero sí muestra que se trata de un estadio en la evolución del compromiso del pensamiento teórico con el derecho positivo. La primera parte del artículo cumple este rol: ella muestra cómo la obra de Kelsen admite ser vista como una continuación del proyecto de positivación de la filosofía del derecho que caracteriza ante todo a la literatura jurídica del siglo XIX. La segunda pretensión es, en cambio, propiamente hermenéutica. El tratamiento del problema de la validez de las normas en Kelsen (las razones por las que ellas pueden ser conocidas y las condiciones en que ese conocimiento se produce) se deja comprender de forma completa solo asumiendo su espacio de discusión original, a saber, la filosofía neokantiana. La presentación de la discusión neokantiana a este respecto pretende por ello cumplir a la vez un rol introductorio y un rol sustantivo limitado: no da cuenta de una interpretación completa de la obra de Kelsen, pero sí del aspecto fundante de su proyecto. La presentación de ambas corrientes no tiene ninguna pretensión de exhaustividad sino que, al contrario, será efectuada a partir de ilustraciones en exponentes específicos de 
Wilenmann - El camino de la teoría pura del derecho...

estas, cuyo lugar en la evolución o en la discusión respectiva pueda ser considerado representativo.

\section{La teoría del derecho en el contexto de la filosofía del derecho continental decimonónica}

\subsection{La evolución de la teoría del derecho en el siglo XIX}

La obra de Kelsen participa de una evolución de la tradición de tematización teórica del derecho. En particular, la filosofía del derecho del siglo XIX se caracteriza por las tensiones que genera en su propia identidad el creciente compromiso con el derecho positivo, y con ello su creciente rechazo a la reducción del tratamiento teórico del derecho a una disciplina externa y crítica de su contenido. El tratamiento de esas tensiones puede ser presentado como una evolución desde una representación bajo la cual el análisis teórico del derecho es externo a este, es decir, consiste en la determinación de representaciones ideales que legitiman a este y que sirven, por lo mismo, para producir crítica del derecho positivo -aquí la ruptura con la pretensión crítica del derecho natural es por ello solo gradual-, hacia una reducción del tratamiento teórico propiamente jurídico a condiciones inmanentes de sentido de prácticas contingentes. Esto puede ser mejor comprendido viendo distintos estadios ilustrados en obras representativas de estos: el punto de partida que reduce el tratamiento teórico del derecho en buena medida al problema de su legitimidad (ilustrado aquí en Gustav Hugo); el giro hacia la entrega de un concepto funcional del derecho (presente, por ejemplo, en Adolf Merkel); la distinción en el tratamiento teórico del derecho en determinación de condiciones inmanentes de sentido y condiciones trascendentes de legitimación (concepto e idea del derecho en Rudolf Stammler) y la reducción del tratamiento teórico del derecho a un problema estructural, observable en distinta forma en Ernst Bierling y Hans Kelsen.

\subsection{La ciencia del derecho de principios del siglo XIX: Gustav Hugo y los caminos posibles de teorización sobre el derecho pese al compromiso con el derecho positivo}

Aquello que podría denominarse trabajos "teóricos" sobre el derecho de principios del siglo XIX tiende a presentar una estructura ambigua para un lector contemporáneo. Por una parte, y a diferencia general de la tradición del derecho natural racional, la distinción entre la pregunta por el contenido del derecho y la pregunta por la corrección de su contenido -una distinción trivialmente conocida para un lector moderno y que puede asumirse define su modernidad- ya puede encontrarse con un grado relativamente amplio de generalidad. ${ }^{4}$ Por otra parte, esa

\footnotetext{
${ }^{4} \mathrm{Al}$ respecto, véase también VON DER PFORDTEN (2001), pp. 43 ss., quien da cuenta de la forma en que la sustitución gradual del concepto de derecho natural por el concepto de filosofía del derecho es expresiva de un cambio de enfoque.
} 
misma distinción es enfocada de una forma que no es completamente familiar para el lector contemporáneo. Así, el tratamiento de aquello que identifica al derecho como derecho es reconducido a la disciplina cuya función precisamente es dar cuenta de su contenido, a saber, la dogmática, mientras que la filosofía del derecho, y por extensión la tradición de tratamiento puramente teórico del derecho, tendría por objeto tematizar la pregunta por la legitimidad del contenido del derecho.

Una ordenación de esta clase es explícita en una de las fuentes más claras de la realización de la distinción: la Enciclopedia del Derecho de Gustav Hugo. ${ }^{5}$ En ella, la generación de conocimiento jurídico es analizada a partir de tres preguntas: “¿qué es lo jurídico?” (Was ist Rechtens?); “Es razonable que sea así?”; y “¿Cómo devino el derecho en lo que es?”. Las tres preguntas serían tematizadas por sus respectivas disciplinas teóricas: dogmática jurídica, filosofía del derecho e historia del derecho.

Por supuesto, en tanto simple tratamiento de distinción disciplinaria -algo célebremente explotado, por ejemplo, por Hart para evitar caer en un reduccionismo ético semejante al de Kelsen-, la clasificación de Hugo no resulta demasiado interesante en sí: no solo las disciplinas, en tanto agrupaciones sin objeto de referencia necesario, pueden ser arbitrariamente definidas, sino que ante todo esas distinciones disciplinarias tenían a su época pretensiones más bien constitutivas que reconstructivas. En otras palabras: no es solo, como hoy, que el compromiso de la teoría con la práctica disciplinaria ajena sea limitado, por lo que sea siempre posible definir disciplinas científicas de manera distinta a la forma en que tienden a ser entendidas por sus actores. Lo crucial es que en la literatura de principios del siglo XIX esa práctica de autocomprensión del trabajo científico como formando parte de ciertas (sub)disciplinas teórico-jurídicas era más bien inexistente o, al menos, precaria y simplemente en gestación. Quien como Hugo presentaba una distinción disciplinaria en el estudio de un objeto estaba, en realidad, proponiendo dividir el estudio del objeto en esas disciplinas.

Ello no impide, sin embargo, usar la comprensión implícita a la clasificación de Hugo para entender el contexto en el que el proyecto de formación de una teoría del derecho surgió. Visto de esta forma, la clasificación de Hugo devela una tensión entre, por una parte, un compromiso con el derecho positivo dado por la distinción entre dogmática y filosofía del derecho ${ }^{6}-$ la ausencia de

\footnotetext{
5 Vgl. Hugo (1823), pp. 34-37. Sobre la influencia de la obra de Hugo, véase BrockMÖLLER (1997), pp. 47 ss.

${ }^{6}$ Uno podría agregar a la historia del derecho a la lista de disciplinas sin compromisos con juicios de contenido, pero ello sería anacrónico en el contexto del trabajo de Hugo. Ya que la historia del derecho tendría por objeto, en particular, estudiar el espíritu del derecho romano en un contexto en que era parcialmente válido, la historia del derecho poseía una relación interna directa con la dogmática: la distinción, por ello, solo podía ser explicada por Hugo como una distinción entre una disciplina práctica y una disciplina teórica. Eso genera una tensión ulterior entre dogmática y estudio histórico del derecho, lo que no puede ser tematizado aquí. Al respecto, véase solo BROCKMÖLLER (1997), pp. 51 ss.
} 
Wilenmann - El camino de la teoría pura del derecho...

compromiso con este, el derecho natural, implica imposibilidad de distinción- y, por otra parte, la inexistencia de una disciplina de tratamiento teórico del derecho que no implique juicio al contenido. Entre nosotros, la tensión entre asunción de contingencia y pretensión teórica se intenta subsanar distinguiendo las disciplinas que implican juicio de contenido -ya sea juicio de pertenencia del contenido al derecho (dogmática), o juicio de legitimación (filosofía del derecho, ética jurídica, o como quiera llamárselo)- y disciplinas que funcionan con abstracción de contenido pero sin pretensiones críticas (teoría del derecho). ${ }^{7}$ En Hugo, esa tensión se maneja distinguiendo, por una parte, la cuestión puramente formal de entrega de un concepto de "derecho" - a eso se reduce el tratamiento teórico no crítico- y, por otra parte, el problema del tipo de conocimiento que puede obtenerse acerca del derecho (dogmática, filosofía, historia). Esa forma de tratar la tensión, distinguiendo entre la cuestión de entrega de un concepto general y el análisis de aquello que engloba el concepto, puede ser de manera amplia encontrada hasta fines del siglo XIX.

En todas las áreas definidas por Hugo como parte de aquellas en las que se juega la cuestión del conocimiento teórico del derecho, la ciencia del derecho poseía tradiciones a las que acoplarse. Esto es evidente en el caso de la dogmática jurídica, pero es también aplicable al problema de legitimación, el que podía ser fácilmente tematizado a partir de la adaptación de los topoi clásicos del derecho natural racional o, en forma más general, de la filosofía política. En cambio, en la cuestión de la entrega de un concepto de aquello cuyo contenido debe ser determinado o de aquello que debe ser legitimado, y por ello en el tratamiento teórico de la pregunta por la posibilidad de obtener una representación estructural general del derecho con independencia de su tratamiento "filosófico" a la Hugo, la tradición era más bien inexistente. El propio Hugo podía advertir el problema, pero no podía tratarlo más que como un problema putativo resuelto de manera simple dando una definición. Por supuesto, una definición suficientemente amplia permite que todos los enunciados que pueden entenderse en algún sentido comprendidos por el objeto así definidos sean jurídicos. No es casual que al igual que otros contextos en los que pueden encontrarse definiciones simples, por ejemplo en los manuales tradicionales de derecho civil a propósito de la teoría de

\footnotetext{
${ }^{7}$ Véase, por ejemplo, DrEIER (1990), pp. 8 ss.

${ }^{8}$ La Enciclopedia del Derecho de Hugo (1823), cit., pp. 3 ss., se inicia tratando el "concepto de derecho", lo que es efectuado de una forma similar a aquella que, entre nosotros, podría tomar un manual de derecho civil al tratar la "teoría de la ley" o algo similar. BROCKMÖLLER (1997), pp. 59 ss., intenta sistematizar el tratamiento de Hugo de las cuestiones estructurales del derecho, incluyendo el concepto de derecho, como parte de lo que este considera "filosofía" del derecho. Se trataría del análisis de enunciados "teórico-dogmáticos", por oposición a enunciados "filosóficos de filosofía del derecho" -si se quiere: metafísico o a priori- y "empírico dogmáticos" de filosofía del derecho. Con independencia de si esa clasificación es fiel a la obra de Hugo, incluso el intento de sistematización de Brockmöller revela la tensión entre, por una parte, concentrar el conocimiento del derecho como tal en la dogmática y, por otra parte, dar cuenta de estructuras generales de este. Si conocimiento del derecho en tanto derecho positivo se limita a la realización de enunciados de pertenencia del derecho, las estructuras generales no pueden ser analizadas.
} 
la ley, el tratamiento teórico estructural del derecho tampoco cumpla ninguna función más allá de una agrupación formal. En Hugo, ello solo es demostrativo de la concentración del conocimiento de interés en dogmática, historia y filosofía del derecho, propia de la ciencia del derecho de principios del siglo XIX.

Esa concentración en esas tres áreas es expresiva, a su vez, de las formas en que la tradición podía seguir tematizando teóricamente el derecho: en de procesos de explicación histórica, por medio de análisis de su contenido y con procesos de análisis de sus condiciones de legitimidad.

Las formas de proceder que tenía a su disposición, así, la tradición de tratamiento teórico del derecho se dejan dividir así, dependiendo de su relación con el contenido del derecho, en dos: podían o bien hacer depender el tratamiento teórico del derecho del análisis del contenido del derecho, es decir, dogmatizar o historicisar la teoría del derecho o, si se quiere, teorizar las condiciones de validez a partir de consideraciones de contenido o del proceso de realización del contenido del derecho; o bien hacer depender el tratamiento teórico del derecho de una definición funcional o metafísica, es decir, tratarlo como un problema de filosofía del derecho en sentido estricto. El primer camino -el camino de la dogmática teórica- es, como es sabido, el camino recorrido por movimientos como la escuela histórica del derecho o la jurisprudencia de conceptos. ${ }^{9}$ El segundo camino -el camino propiamente teórico- se encuentra presente en el tipo de obras que influyeron en mayor medida en la teoría del derecho continental temprana y que, por ello, puede considerarse como el camino propiamente jurídico hacia Kelsen. Un ejemplo de una propuesta de teorización de esta segunda clase se encuentra en la conceptualización final o funcional del derecho, representativa del tipo de inquietudes presentes en parte de la literatura jurídica de mediados del siglo XIX tras la llamada implosión del idealismo. ${ }^{10}$ En ellas, la semántica normativa abstracta en la determinación del objeto del derecho es reemplazada por una definición de funciones políticas en sentido amplio. El tratamiento teórico del derecho sigue, sin embargo, teniendo lugar desde fuera. El camino de la teoría del derecho de la segunda mitad del siglo XIX a este respecto no consiste, por ello, en pura disolución de la pretensión legitimatoria de la filosofía moral o del derecho natural. Al contrario, parte importante de esa pretensión sigue estando presente, como puede ser percibido inmediatamente, por ejemplo, en Rudolf Stammler. ${ }^{11}$ El camino consiste antes bien en la internalización del discurso teórico sobre el derecho sin que ello implique tratamiento directo del contenido.

Por supuesto, camino dogmático teórico y camino propiamente teórico solo marcan ideas generales; en los hechos, el tratamiento teórico del derecho del

\footnotetext{
${ }^{9}$ Al respecto BROCKMÖLLER (1997), pp. 83 ss.

10 Aquí son ejemplares los escritos de teoría del derecho de Adolf Merkel. Véase, por ejemplo, MERKEL (1899), pp. 639 ss. Véase también, con ulteriores referencias, BROCKMÖLLER (1997), pp. 238-245.

11 Infra.
} 
Wilenmann - El camino de la teoría pura del derecho...

siglo XIX tiende a adoptar en mayor o menor medida ambos enfoques al mismo tiempo. Así, el desarrollo tardío de la dogmática del derecho público y de proyectos que le acompañaron -ante todo la teoría del Estado-, ${ }^{12}$ puede en forma correcta considerarse crucial en la generación de una representación verosímil de la lógica general del derecho a partir del proceso de formación de un sistema de reglas positivas. ${ }^{13}$ Ello hace que el tratamiento de la cuestión bajo una distinción categórica como la aquí presentada -teoría dogmática/histórica del derecho aquí, teoría abstracta del derecho allá- sea irremediablemente impreciso. Pero ella sirve para poder concentrarse en el enfoque metodológico de tratamiento directo del tipo de problemas que ocupan a la teoría del derecho consolidada.

\subsection{La teoría del derecho como epistemología y filosofía política: concepto de derecho e idea del derecho en Rudolf Stammler}

La influencia de las distintas tensiones que caracterizan a la teoría del derecho de mediados del siglo XIX - a saber, desprendimiento de la teoría del derecho tanto del estudio del contenido del derecho como de la filosofía política y de sus equivalentes, sin por ello poder entenderse a sí misma con una lógica inmanente es también perceptible en uno de los autores más influyentes en la Alemania de fines del siglo XIX, Rudolf Stammler, en quien el parentesco con la teoría del derecho de principios del siglo $\mathrm{XX}$ y, con ello, con Hans Kelsen, ya es apreciable de forma directa. Su obra ya tiende a presentarse como análisis puramente interno de condiciones de sentido, pese a mantener una fijación en la legitimación externa similar a la de Merkel. Como ambas pretensiones son incompatibles -uno no puede querer a la vez presentar un análisis de pura estructura interna y mantener una orientación funcional en su explicación-, la teoría de Stammler necesitaba marcar la diferencia. La distinción entre los términos de "concepto" del derecho e "idea" del derecho, explicada a continuación, cumple esta función.

La obra de Stammler pretende ofrecer una filosofía del derecho que pueda ser considerada propia de este. En eso, existe incompatibilidad con la tradición de inclusión de la filosofía del derecho en la filosofía política legada por el derecho

\footnotetext{
12 Para una descripción somera del proceso en cuestión, véase solo MÖLLERS (2008), pp. 15-21.

13 Así, uno puede correctamente caracterizar la evolución del análisis teórico del derecho como el paso de una concepción histórico-dogmática influida ante todo por el derecho privado propia de principios del siglo XIX, hacia una concepción teórica influida ante todo por el derecho público, la que dominó sobre todo durante la primera mitad del siglo XX. Esto es generalmente advertido en estudios recientes (por ejemplo BROCKMÖLLER (1997), pp. 271 ss.), pero ya podía ser advertido en 1874 por un penalista como Adolf Merkel (véase MERKEL (1899), p. 297). Esa evolución ha dejado, en particular en el mundo de habla alemana, marcas evidentes. Así, las cátedras de historia del derecho y de argumentación jurídica (o teoría del método) tienden a ser dependientes de cátedras de derecho privado, mientras que las cátedras de teoría del derecho tienden a ser dependientes de cátedras de derecho público. En cambio, probablemente por el vínculo con la tradición de discusión de teoría de la pena, las cátedras de filosofía del derecho tienden a ser dependientes de las cátedras de derecho penal.
} 
natural racional. La lejanía de Stammler frente a la tradición de análisis del derecho desde fuera puede verse ya en su autodescripción como "jurista filosófico" antes que como "filósofo del derecho" presentada en un temprano escrito programático crítico de la escuela histórica del derecho. ${ }^{14} \mathrm{La}$ teoría del derecho sería generalización de conocimiento del derecho desprendido de su contenido a partir del conocimiento obtenido precisamente de su contenido y no, en cambio, inserción en sistemas de pensamiento externos. Esta comprensión aparentemente paradojal de la teoría del derecho, no extraña a la propia escuela histórica del derecho, es explícita en la obra de Stammler. De acuerdo con este, la teoría del derecho trataría precisamente de la respuesta a "dudas de tipo general a cuyo planteamiento el jurista necesariamente llega y sin que pueda responderlas solo a partir del conocimiento de su propio derecho especial o de cualquier otro derecho". ${ }^{15}$

Ya el planteamiento del tipo de cuestiones que interesan a la teoría del derecho es sumamente parecido a los problemas que preocuparán más tarde a esta. Así las preguntas que por su estructura requerirían de reflexión teórica del derecho serían, por ejemplo, si "aquello que es derecho, también debiera serlo" y "cómo es posible el surgimiento de derecho a partir de una ruptura en el derecho". ${ }^{16} \mathrm{Si}$ bien la primera pregunta recuerda a las viejas preguntas de la filosofía del derecho y parece con ello anunciar el mantenimiento de la tradicional pregunta por la legitimidad en el centro de la teoría del derecho -en eso es radicalmente antikelseniana-, la segunda pregunta mantiene solo parcialmente ese posible anuncio de continuación de la tradición de la filosofía del derecho entendida como parte de la filosofía política, pero reproduce al mismo tiempo de forma exacta la pregunta central a las que las construcciones más extrañas y relevantes de Kelsen (la norma fundante básica y la cláusula alternativa táctica) intentan responder. Así, no solo la distinción entre primera constitución histórica y norma fundante básica se ve afectada por el problema de la ruptura, sino también la explicación de la validez de normas surgidas con anterioridad a sus normas lógicamente superiores. ¿ $\mathrm{Si}$ el tiempo y por lo tanto el carácter posterior de las normas inferiores (o al menos de su validación) es esencial a su existencia, cómo pueden existir normas válidas anteriores a la primera constitución histórica y sin validación explícita por parte de esta? Esto, que fuera de contexto podría considerarse una aporía revelada solo a partir de las investigaciones rupturistas de la teoría del siglo XX, formaba ya parte del horizonte central de preguntas en la cultura jurídica decimonónica tardía.

Por cierto, en lo que interesaba a Stammler, el objeto del planteamiento de ambas preguntas era dar cuenta de la insuficiencia de los medios de la escuela histórica del derecho para responderlas adecuadamente. Sin embargo, su posición representativa de la filosofía del derecho de fines del siglo XIX se ve ante todo demostrada en el tipo de respuestas a las que Stammler podía llegar. En Stammler

\footnotetext{
14 Así en Stammler (1925), pp. 7-8. Con mayor detalle, véase Kersting (2002), pp. 38-41.

15 STAMMLER (1925), cit., p. 9.

${ }^{16}$ Ibid.
} 
Wilenmann - El camino de la teoría pura del derecho...

no se trata directamente de mostrar la necesidad de mantener el vínculo con criterios de legitimación supraformales, sino ante todo de mostrar que la idea misma de derecho requiere del manejo de criterios epistemológicos de reconocimiento de validez que no pueden ser solo internos a un sistema contingente. Si se quiere: la estructura y no la función del derecho lo definirían. Esa estructura no aparece, sin embargo, como puramente contingente a una construcción cultural determinada, sino como un problema trascendente de reconocimiento de un objeto. Nuestras formas generales de comprensión del mundo, y no en cambio la estructura específica del objeto "derecho" o las razones por las cuales lo hemos construido, determinarían al concepto del derecho. En las elocuentes palabras de Kersting, Stammler "epistemologiza completamente el problema de validez del derecho surgido a partir de violencia y desplaza las más tradicionales consideraciones legitimatorias a un ámbito iusfilosófico especial". ${ }^{17}$

El giro epistemologizante que ya puede observarse en Stammler es revelador de las inquietudes y los problemas de la filosofía del derecho de fines del siglo XIX y que anticipa completamente a obras como las de Kelsen. Ya la elección de las dos preguntas cardinales de la filosofía del derecho de Stammler muestra el espíritu de su filosofía. Ambas preguntas tratan sobre problemas que el ethos institucional-formal (imprecisamente dicho: el ethos positivista) del derecho de fines de siglo XIX podía hacer aparecer como anómalas y, por ello, demostrativa de sus propias limitaciones. Por supuesto, ese es el punto de Stammler: pese a la aparente autosuficiencia de la ciencia del derecho, preguntas que afectan sus mismas condiciones de posibilidad no pueden ser respondidas sin criterios trascendentes. Enmarcado en su ataque de juventud contra la escuela histórica del derecho, Stammler pretendía ciertamente ante todo mostrar que preguntas centrales que necesariamente afectan el trabajo de los juristas no pueden ser respondidas por ningún tipo de empirismo, incluyendo el empirismo jurídico dado por la reducción del derecho a su contenido o a las condiciones de producción de su contenido (y con eso tampoco por el dogmatismo teórico de la escuela histórica del derecho).${ }^{18}$ Pero mucho más interesante que analizar el mérito de su crítica a la escuela histórica es ver que el planteamiento de ambos problemas implica, al mismo tiempo, aceptación de la normalidad del funcionamiento formalinstitucional del derecho como parte de su constitución estructural. Descrito plásticamente: al igual que Kelsen, la teoría de Stammler supone aceptar una descripción de la validez del derecho asimilable a la entregada por el primero al caracterizar un sistema dinámico -Stammler hablaba de "determinaciones del derecho sobre sí mismo"-, ${ }^{19}$ ya que justamente esa descripción es la que pone en el centro de las inquietudes teóricas a la aporía de la generación de derecho pese a su ruptura.

\footnotetext{
${ }^{17}$ Kersting (2002), cit., p. 42.

18 Así también Ibid., pp. 38-39.

19 Véase STAMmLER (1925), pp. 30-31.
} 
En el tratamiento mismo, en cambio, de las condiciones de posibilidad del derecho, las respuestas de Stammler mantienen la idea de que solo pueden ser respondidas con criterios trascendentes, aunque rompiendo parcialmente con la más tradicional pretensión de hacerlo a partir de reflexiones sobre legitimidad normativa trascendente. Esa ruptura no se manifiesta en el tratamiento de la primera pregunta, la que en sí exige una pérdida de compromiso con la pretensión de puro tratamiento conceptual inductivo: la respuesta por la corrección del derecho no admite una respuesta con pretensiones puramente inmanentes como la de la norma fundante básica. La defensa de una cierta comprensión de la tradición del derecho natural frente a la escuela histórica del derecho ${ }^{20}$ es el resultado necesario al que la forma de planteamiento del problema de "la idea del derecho" podía llevar a Stammler. La ruptura con la tradición de la filosofía del derecho derivada del derecho natural racional es, en cambio, clara en la respuesta a la segunda pregunta. Según Stammler, el proceso de transmutación de la violencia pura o de la voluntad no mediada por normas validantes en derecho solo podría ser explicado a partir de consideraciones trascendentes tomadas de reflexiones sobre las condiciones de reconocimiento de unidad de concepto en relación con un fenómeno; solo así podría encontrarse "una característica común para todas las formas de creación del derecho [ie. gracias a/sin/contra derecho vigente JW]". ${ }^{21}$ En otras palabras, el reconocimiento contingente de derecho presupondría siempre un concepto trascendente de derecho. Este se manifestaría de forma tácita en el reconocimiento normal de derecho y de forma abierta en el reconocimiento de derecho tras ruptura. ${ }^{22}$ En ambos casos se trataría solo de formas de conocimiento (ratio cognoscendi) de aquello que es; la esencia del derecho (su ratio essendi) solo podría comprenderse, en cambio, por medio de la entrega de un concepto -y "concepto" aquí quiere decir: conjunto de condiciones bajo las cuales elementos determinados son reconocidos como una unidad con identidad particular- de este.

El manejo de las distintas inquietudes de Stammler tiene consecuencias cruciales en la estructuración de su propia representación de filosofía del derecho. Mientras en la tradición derivada del derecho natural la primera pregunta de Stammler contiene lógicamente a la segunda -es irrelevante que el derecho surja de violencia; sigue siendo derecho si tiene contenido de derecho-, la estrategia de Stammler exige diferenciar la pregunta por la legitimidad del derecho de la pregunta por la validez del derecho incluso en los casos anómalos de normas surgidas sin normas superiores validantes. En Stammler, ello se estructura distinguiendo una "idea" del derecho, esto es, una representación ideal de lo que este debe ser, la que por lo mismo puede dar cuenta de sus condiciones de legitimidad, de un "concepto" de derecho, cuya estructura es ante todo

\footnotetext{
${ }^{20}$ Ibid., pp. 18 ss.

21 Ibid., p. 31.

22 Ibid., p. 34.
} 
Wilenmann - El camino de la teoría pura del derecho...

epistemológica y que simplemente permite reconocer unidad. ${ }^{23} \mathrm{El}$ tratamiento de ambas cuestiones forma el centro de la filosofía del derecho de Stammler. En lo que interesa aquí, la pregunta por el "concepto" de derecho pretende ser respondida con una especie de inferencialismo tomado del método trascendental de la filosofía crítica: a partir de la observación de un fenómeno (en este caso: el fenómeno de la necesidad de regulación jurídica en sociedades humanas), Stammler pretendía establecer las condiciones de posibilidad del fenómeno y, partiendo de la base de la realidad del fenómeno, deducir la realidad de sus condiciones de posibilidad, lo que implica la existencia del concepto. ${ }^{24}$

El concepto de derecho entregado por Stammler bajo utilización de su pretensión inferencial no es en sí particularmente original ni interesante: el derecho sería "la voluntad vinculante, soberana e inquebrantable" (Recht ist unverletz̧bar selbstherrlich verbindende $W o l l e n) .{ }^{25}$ Su intuición trascendental, sin embargo, hace que la respuesta intente encontrar su fundamento en un proceso categorial: como el fenómeno "derecho" no puede encontrar un equivalente en la naturaleza, el conocimiento y observación del derecho no puede ser dependiente del proceso categorial de observación de la naturaleza (i.e. de la sintetización de las relaciones de la materia por medio del principio de causalidad). El equivalente, y por lo tanto la condición de posibilidad del derecho, Stammler lo encuentra en el principio de finalidad, es decir, en la forma en que la voluntad se organiza en torno a la consecución de un fin determinado. ${ }^{26}$ Esa forma específica de organización hacia

\footnotetext{
${ }^{23}$ Véase el ensayo "Wesen des Rechts und der Rechtswissenschaft" de 1913 en STAMMLER (1925), pp. 387 ss.

${ }^{24}$ Ibid., pp. 388, 399 ss. La insistencia de Stammler sobre la reflexión en torno al fenómeno real del derecho y, por ello, sobre la realidad del principio de finalidad, tiene que ser entendido como el objeto central de crítica de Kelsen a Stammler. Su crítica explícita va, sin embargo, más allá. En su escrito de habilitación, Kelsen sostiene que el conocimiento teleológico introducido por Stammler en oposición al conocimiento causal -es decir, la oposición entre principio de causalidad y principio de finalidad- se dejaría, en realidad, reducir al primero (véase KELSEN (1923), pp. 57-65). El fin constituiría o bien una descripción de un estado de cosas querido por el sujeto y, por lo mismo, existente en tanto volición (la voluntad es un estado de cosas y, por lo mismo, pertenecería a la categoría del ser), o bien una descripción causal compleja ("el objeto de la acción cardiaca es proveer de sangre al cuerpo"). Esto parece incompatible con la afirmación fácilmente reconocible en distintos textos del mismo período (véase, por ejemplo, KELSEN (1968b), p. 38), en relación con que la oposición entre ser y deber postulada por él es, en realidad, lo mismo que la distinción entre causalidad y finalidad. Sería un error, sin embargo, conformarse con esa aparente contradicción de conceptos. La identidad solo se da si se postula un concepto "estrictamente objetivo" (Ibíd.) de fin, en el cual este sea identificado no con el acto de querer, sino con su sentido normativo. La crítica a Stammler parece limitarse, con ello, a la confusión entre el estado mental de querer un estado de cosas y el sentido de postular ese estado querido como un deber. Aunque Kelsen muestra de manera convincente que Stammler parece haber confundido ambas cosas, el hecho que la crítica parezca poder extenderse solo a la confusión muestra la cercanía que tienen, en ese aspecto, Stammler y Kelsen.

${ }^{25}$ STAMMLER (1925), p. 409.

${ }^{26}$ Ibíd., pp. 400 ss. Sobre la distinción categorial de Stammler entre causalidad y finalidad, véase con mayor detalle KERSTING (2002), pp. 46-48.
} 
un fin tendría lugar en el derecho por medio de la coacción. Es decir, la consecución del fin del derecho se encontraría, en el fenómeno en cuestión, necesariamente ligada a un medio específico, la idea de coacción, con lo que este integraría su esencia ("voluntad vinculante", que se considera a sí misma inquebrantable). Con ello, el concepto de derecho de Stammler es aparentemente indistinguible de un concepto moderno tradicional como el de Merkel o como aquello que aún es posible encontrar en manuales de introducción al derecho o de derecho civil, pero se encuentra conformada por intuiciones cuya fundamentación es desarrollada con medios mucho más sofisticados tomados de la filosofía kantiana y neokantiana. Su sofisticación no implica, por supuesto, ni consistencia ni corrección. La mezcla de motivos tradicionales de la tradición del derecho natural/filosofía política con una epistemologización sui generis del concepto de derecho es difícilmente conciliable en su interior. Que ella es, sin embargo, posible de ser llevada a cabo de forma consistente por medio de radicalización, no puede ser visto de mejor forma en ninguna parte que en la Teoría Pura del Derecho. El compromiso ideológico radical de Kelsen con la idea de existencia del derecho le permite suprimir directamente el problema que le preocupaba a Stammler: la norma fundante básica no es más que una disolución de las anomalías dadas por la ruptura de derecho a partir del método trascendental.

\subsection{La teoría del derecho como teoría de las condiciones de validez de la norma: Bierling}

La ruptura metodológica en la teoría del derecho puede reconocerse de forma todavía más clara en la Juristische Prinzipienlebre de Ernst Bierling. Mientras en Stammler los problemas teórico-estructurales mantienen una cierta tensión con los problemas de legitimación, la teoría del derecho aparece en buena medida reducida a una cuestión estructural en Bierling. Al igual que en Stammler, el tratamiento teórico del derecho es visto por Bierling como un problema de determinación de condiciones de posibilidad y, con ello, es efectuado a partir de una especie de inferencialismo transcendental. Ese inferencialismo trascendental no toma, sin embargo, la forma de una teoría del conocimiento jurídico en cuanto teoría de la capacidad de representación del derecho bajo analogía con la teoría del conocimiento kantiana. De forma mucho más sencilla, la cuestión es vista como una teoría de las condiciones bajo las cuales una norma puede ser reconocida como vinculante (es decir, como derecho). ${ }^{27}$

La conversión de la teoría del derecho en una teoría de las condiciones de posibilidad de las normas jurídicas sigue en Bierling un camino similar a la teoría general del derecho de Stammler. El equivalente a la teoría del derecho -la teoría de los principios jurídicos (juristische Prinzipienlebre) $-^{28}$ tendría por objeto dar cuenta

\footnotetext{
27 Véase ante todo BIERLiNG (1979), \3 pp. 30 ss.

${ }^{28}$ En el sistema de Bierling, "teoría de los principios jurídicos" constituye una subcategoría de la "filosofía del derecho en sentido amplio". "Filosofía del derecho en sentido amplio" designaría en general al tratamiento teórico del derecho, lo que puede dividirse en la determinación formal de sus
} 
Wilenmann - El camino de la teoría pura del derecho...

de aquellos conceptos necesarios a todo ordenamiento jurídico con independencia de su contenido. ${ }^{29}$ Una descripción de esta clase podría aplicarse, por cierto, a conceptos sustantivos con pretensiones de integración del derecho: la teoría del derecho natural podría sin problemas decir que su objeto es investigar "conceptos necesarios a todo ordenamiento jurídico". Para evitar esto, también Bierling necesitaba recurrir a una separación disciplinaria clara entre teorías con pretensiones de postulación/descubrimiento de contenidos necesarios (derecho natural), de condiciones mínimas de legitimidad o de contenidos que debieran formar parte del derecho (filosofía del derecho), y el problema "de naturaleza puramente formal" de los principios del derecho en la terminología de Bierling. ${ }^{30}$ El postulado de esta "naturaleza puramente formal" es crucial en la comprensión de la teoría de Bierling.

Al igual que en Stammler y, en general, en la más o menos dualista filosofía del derecho de fines del siglo XIX, la explicitación de la naturaleza "puramente formal" de la teoría de los principios jurídicos pretende mostrar, por cierto, su oposición frente a construcciones conceptuales con pretensiones también sustantivas, es decir, con contenido normativo. Sin embargo, lo crucial en Bierling es un segundo aspecto de la "formalidad" de la teoría de los principios jurídicos: su naturaleza "puramente formal" también tiene compromisos epistémicos en su rechazo a un realismo jurídico ingenuo -sea escéptico (realismo) o creyente en algo así como el derecho natural-, esto es, en la ruptura con la pretensión de que existe algo así como el derecho sino como idea formal. Tanto los neokantianos tempranos, por ejemplo, aunque con particular verosimilitud Hermann Cohen, ${ }^{31}$ como la filosofía del derecho de fines del siglo XIX de Rudolf Stammler, pretendían aplicar el método trascendental precisamente por existir un objeto real, de cuyo conocimiento concreto pudieran extraerse sus condiciones de existencia y conocimiento a priori. En Bierling, en cambio, existe reconocimiento expreso de que ante inexistencia de un objeto real, la existencia del concepto universal solo puede ser asumida como "un simple postulado". "Esto es, el concepto no tiene ninguna implicancia ontológica directa, con lo que su existencia solo puede tener un componente por así llamarlo puramente "mental" o "ideal" (en Bierling: de reconocimiento, tradicionalmente entendido como reconocimiento psicológico). La teoría del derecho funcionaría así por explicitación de aquello que asumimos

condiciones de posibilidad y, por lo mismo, de sus conceptos necesarios - “teoría de los principios jurídicos"-, y en determinación de condiciones de reconocimiento abstracto de valor a normas jurídicas -"teoría de la idea del derecho" o "filosofía del derecho en sentido estricto"-. Ya la elección de los nombres de las distinciones disciplinarias (ante todo, "idea del derecho") recuerda a Stammler o al neokantismo de inspiración sur-alemana de Emil Lask y Gustav Radbruch. Sobre la clasificación de Bierling, véase solo BROCKMÖLLER (1997), pp. 254-256.

${ }^{29}$ Ibid., $\ 1$ p. 1. La formulación de la descripción del objeto de la teoría de los principios jurídicos por parte de Bierling es prácticamente idéntica a la famosa descripción del objeto de la teoría del derecho de Hart.

${ }^{30}$ Ibid., p. 1-2.

31 Infra.

32 Ibid., p. 2. 
existe cuando postulamos la existencia de algo así como "el derecho" o "un sistema jurídico". Esa asunción no implica, como podría verse en Stammler, que el objeto asumido tenga entidad real: aunque asumamos su existencia, el objeto sigue siendo vacío. ${ }^{33}$ Pero aquello que no puede negarse que exista es, en cambio, la asunción misma de la existencia de ciertos contenidos conceptuales propios de nuestra comprensión (seguramente contingente) del derecho.

La estrategia argumentativa de Bierling para demostrar esto es brutalmente sencilla, pero no por ello poco convincente: todo aquel que "practique alguna forma de ciencia jurídica" necesita postular tácitamente que los principios jurídicos (es decir, los conceptos generales inmanentes al derecho) existen. Hablar de derecho entre distintos pueblos o en distintos períodos constituiría un abuso del lenguaje a menos que pueda reconocerse unidad conceptual. Las ciencias jurídicas muestran, en cambio, necesidad de proceder por medio de generalización de conceptos; ellas asumen que al comparar distintas prácticas normativas que tienen lugar en unidades político-territoriales diversas comparan distintos "derechos" (derecho comparado), o que las prácticas normativas de distintos períodos son reconducibles a un concepto general (historia del derecho). Quien, en cambio, critica la asunción de la existencia de las categorías generales y, al mismo tiempo, hace cualquier tipo de ciencia jurídica (sea investigación histórica, dogmática, derecho comparado), se contradice a sí mismo. ${ }^{34}$ Por supuesto, el escéptico radical no tiene por qué asumir que existen fenómenos reconducibles a conceptos asimilables y puede denunciar a toda ciencia del derecho como un fraude. Eso hace que los principios formales del derecho solo constituyan "un simple postulado": no tienen nada que ofrecer contra el escepticismo radical más que el hecho que las convenciones lingüísticas generales las avalan.

En la entrega misma de un concepto de derecho, la teoría de los principios de Bierling se construye combinando postulados funcionales tradicionales y formulaciones que no pueden encontrarse en las definiciones teóricas tradicionales del derecho. Que el derecho tenga relaciones inmanentes con la ordenación del comportamiento externo ${ }^{35}$-que ese sea su "objeto" o "fin"- no puede, por ejemplo, sorprender a nadie en el contexto de fines del siglo XIX y, por lo mismo, no resulta demasiado interesante. Tal vez precisamente por ello, esta asunción permanece no problematizada en la exposición de la Prinzipienlebre; su corrección no es demostrada por inferencia transcendental. En cambio, que la unidad conceptual misma del derecho venga dada completamente por el concepto de

\footnotetext{
33 En esto, el paralelo con Kelsen es evidente. La crítica a toda forma de realismo jurídico constituye uno de los tópicos centrales de su obra temprana. Así por ejemplo la célebre contraposición entre el vicio de observación sociológica y el vicio constituido por la teoría del derecho natural ya presente en el prólogo a la segunda edición de su escrito de habilitación (KELSEN (1923), p. V) o aún más enfático en artículos del mismo período: el derecho "desde un principio no constituye nada que pueda ser real" (KELSEN (1968a), p. 1238). En la Teoría Pura del Derecho, la contraposición aparece ya en la primera página (KELSEN (1960), p. 1).

34 Bierling (1979), p. 2-3.

${ }^{35}$ Cfr. Ibid., $\int 3$ pp. 19 y 20 ss.
} 
Wilenmann - El camino de la teoría pura del derecho...

norma -en Bierling, esto tiene lugar por medio del postulado de que el concepto de derecho se construye a partir de una reconstrucción de un medio específico de ordenación del comportamiento, a saber, de la norma, cuyo sustrato real es un imperativo pero cuyo sentido no se deja reducir a ese sustrato real-, que la norma tenga una forma generalmente reducible a la estructura de imperativos y que las normas jurídicas se distingan de otras normas no directamente por la exigencia de cumplimiento coactivo, sino por el tipo de reconocimiento (Anerkennung) que reclaman, poseen y que les entrega sentido independiente de su carácter volitivo, ${ }^{36}$ mezcla asunciones generales presentes en la teoría de los imperativos, reformulada mediante una pretensión de demostración crítica (si se quiere: lógico transcendental) ausente en las formas tradicionales de las teorías del derecho imperativistas.

Lo anterior es explícito en la demostración de la reductibilidad del concepto del derecho a la estructura de la norma. Dicha demostración es efectuada, en palabras de Bierling, de forma "especulativa"; ${ }^{37}$ esa especulación es, en realidad, "lógico-transcendental". El argumento de demostración tiene la siguiente forma: la existencia de un estado jurídico implica a su vez la asunción de la posibilidad de un estado no jurídico, el cual determina negativamente el contenido del segundo: lo necesario para la superación del estado no jurídico integra al estado jurídico. Asumida hipotéticamente la existencia de un estado formal de naturaleza, su superación requiere la postulación de una primera norma jurídica -al estar temporalmente determinada, podría llamarse "primera constitución histórica", aunque los comentaristas de Bierling tienden impropiamente a asimilarla a la "norma fundante básica"- que convierta el estado naturaleza en estado civil. A diferencia de la tradición del derecho natural, la hipótesis de Bierling no tiene por objeto establecer las condiciones que legitiman ese paso, sino solo dar cuenta de su estructura formal mínima para que el paso al estado jurídico tenga lugar del todo. Por supuesto, un estado jurídico en el sentido moderno del concepto contiene siempre elementos que le dan un carácter dinámico, es decir, que permiten la creación de normas. Esas "reglas de segundo grado" sabemos que se dejan describir con una estructura distinguible de la estructura de la norma como fuente de obligación. Con ello es posible pensar que aquello que permite pasar de un estado de ausencia de derecho a un estado civil es, en realidad, una convención sobre normas de competencia y no una norma de obligación, con lo que la norma que obliga no constituiría la estructura mínima necesaria del derecho. Esa asunción es, según Bierling, falsa o, al menos,

\footnotetext{
${ }^{36}$ Por supuesto, el acto de reconocer, si es comprendido psicológicamente, se deja reducir también a un estado de cosas. Con ello, la plausibilidad de la tesis de Bierling depende de la capacidad de postular una conversión de sentido del carácter subjetivo-real del imperativo hacia el carácter objetivo-ideal de la norma a partir de un estado de cosas subjetivo-real (en Bierling: reconocer). Según Kelsen, precisamente por ello la teoría de Bierling no dejaría nunca de ser, en realidad, sociología (o realismo), con lo que no podría entregar una explicación real a la validez de las normas. Véase KELSEN (1923), pp. 355 ss.

${ }^{37}$ BIERLING (1979), \ 3 p. 35.
} 
incompleta. Sin postular que el primer elemento de superación del estado de no derecho tenga forma de norma, es decir, de exigencia de cumplimiento, las normas facultativas se dejarían desobedecer generalmente, con lo que el reconocimiento general exigido por el derecho no tendría lugar. Antes que la concesión de potestades de creación de normas, aquello que permite el paso al sistema jurídico es el otorgamiento de carácter obligatorio a su contenido, incluyendo aquellas normas que permiten crear otras normas: esas normas deben ser reconocidas. Con ello, la estructura de la norma forma parte de la estructura fundante del sistema, ya que esa es una condición de posibilidad de este. El concepto de norma sería inherente al concepto de derecho.

\subsection{Hans Kelsen en el contexto de la evolución de la teoría del derecho del siglo XIX y de principios del siglo XX}

En todos los ejemplos entregados (Merkel, Stammler y Bierling), existe una notable uniformidad pese a la completa disparidad en las pretensiones de las teorías del derecho correspondientes. Todos se encuentran comprometidos con un cierto ethos formalista (aunque bien podría decirse: institucionalista), bajo el cual la reducción del derecho al derecho reconocible formalmente solo puede aparecer como autoevidente; todos expresan ese compromiso teórico institucional a partir de una separación dual de disciplinas teóricas del derecho que, en lo esencial, se deja reducir a la distinción entre filosofía del derecho y teoría del derecho, siendo esta última el objeto central de interés de todas las exposiciones; y tanto Stammler como Bierling pretenden resolver las perplejidades que entrega el tratamiento teórico del derecho rompiendo con la pretensión de análisis de legitimidad mediante reconstrucciones de unidades conceptuales dadas, por un lado, por la postulación de un principio epistemológico categórico de "finalidad" y, por el otro, por la utilización de una suerte de inferencialismo derivado del método transcendental kantiano sin compromiso con el conocimiento de objetos reales. La teoría pura del derecho participa completamente de este conjunto de fijaciones, pese a que las radicaliza todas: ${ }^{38}$

- El compromiso formal-institucional no se expresa por distinción entre disciplinas teóricas, sino por reducción de todo análisis teórico al análisis teórico formal. El resto es directamente eliminado como objeto digno de teoría por asumir o bien un realismo insostenible o bien por no respetar estándares mínimos de cientificidad. ${ }^{39}$

\footnotetext{
${ }^{38}$ Precisamente por ello, la estrategia de crítica de Kelsen frente sus antecesores y contemporáneos -como Bierling y Stammler- consiste en mostrar la forma en que sus teorías se dejarían reducir a las dos formas tradicionales del empirismo y del derecho natural. Al ser insostenibles ambas formas de proceder, las teorías que se funden aunque sea implícitamente en ellas serían, a su vez, insostenibles. Al respecto, véase solo PAULSON (1990), pp. 160 ss.

${ }^{39} \mathrm{Al}$ respecto véase solo DREIER (1990), pp. 27 ss.
} 
Wilenmann - El camino de la teoría pura del derecho...

- Los tópicos transcendentales y categóricos tomados de la filosofía kantiana son retomados por Kelsen, pero con el objeto de lograr estructurar un sistema interno hermético consistente y no, en cambio, para mostrar la integración de nuestra comprensión del derecho en las categorías normales de conformación de la experiencia. Dicho de forma brutalmente simple: la teoría del derecho de Kelsen asume que una representación verosímil de este ni siquiera acepta postular la existencia de algo así como "una cosa en sí" a partir de la cual el objeto conocido aparezca como su propio reflejo en el sujeto; en Kelsen, el derecho -al igual que la naturaleza- es reducido a pura prestación común de los sujetos, con lo que su exposición teórica implica reconstrucción de las asunciones comunes necesarias de los partícipes de la generación de un mundo normativo. ${ }^{40}$

Esta posición de la obra de Kelsen en la evolución de la filosofía del derecho continental desde el siglo XIX confirma que esta se deja describir correctamente dando cuenta de tres aspectos. En primer lugar, la existencia de la mayor parte de los tópicos que son usualmente asumidos como "revolucionarios" muestra que la obra de Kelsen se deja ver antes como explicitación de su contenido potencial a partir de la radicalización de la forma de proceder que le antecede que como obra revolucionaria y autosuficiente. En segundo lugar, esa radicalización tiene lugar ante todo por la pretensión de conseguir "la elaboración de una teoría del derecho postmetafísica consecuente", ${ }^{41}$ pese a surgir precisamente de las obsesiones propiamente metafísicas relativas a la ontología de las normas que pueden reconocerse en Bierling y, sobre todo, en Stammler. Este segundo aspecto se deja confirmar de mejor forma revisando, en lo que sigue, la influencia de la filosofía neokantiana. En tercer lugar, pese a que las escuetas referencias presentes en su obra más conocida, la segunda edición de la Teoría Pura del Derecho, hagan parecer que el horizonte de discusión de Kelsen en la comunidad jurídica se encuentra constituido por la tradición positivista, el análisis del contexto de trabajo de este muestra que ello claramente no es así: su horizonte de discusión es la ciencia jurídica de fines del siglo XIX y principios del siglo XX, preocupada ante todo en el establecimiento de una teoría del derecho que no resultara metafísicamente ingenua. La relación de Kelsen con el neokantismo también permite confirmar esto.

\section{Neokantismo, filosofía del derecho y la teoría pura del derecho}

\subsection{Introducción: influencia general del neokantismo en la filosofía del derecho}

La obra de Kelsen se encuentra conformada en sus aspectos cruciales por afirmaciones que bien pueden considerarse brutales. Buena parte de las más famosas de esas afirmaciones -la reducción de las normas a la estructura de la

\footnotetext{
$40 \mathrm{Al}$ respecto, véase KELSEN (1968b), p. 39.

41 Así Dreier (1990), p. 23.
} 
norma de sanción, la disolución de los conceptos de derecho subjetivo, persona, Estado, interpretación jurídica, la postulación de teorías llamativas como las de la norma fundante básica y de la cláusula alternativa tácita- tienen lugar en el contexto interno del análisis del derecho, es decir, forman parte de la teoría pura del derecho y no de su sustento externo. Su sustento externo se encuentra, sin embargo, conformado por enunciados igualmente brutales y cuyo potencial provocador no se reduce a la cultura jurídica, sino que la trasciende. En particular, su teoría del conocimiento jurídico se encuentra conformada por dos afirmaciones: la reducción de todo conocimiento posible al conocimiento de las ciencias naturales y al conocimiento del derecho, y la imposibilidad del conocimiento normativo más allá del conocimiento del derecho positivo (escepticismo ético). Las dos afirmaciones parecen ser distinguibles entre sí y tener distinto potencial polémico: mientras el escepticismo ético es un tópico que recorre la filosofía desde la Antigüedad, la idea de que más allá de las populares ciencias naturales el único conocimiento científico posible sea precisamente jurídico solo puede parecer extraña. En realidad, la segunda afirmación se deriva directamente de la primera en Kelsen. Lo mismo sucede con buena parte del contenido de su teoría del derecho: los conceptos eliminados y disueltos, en general, en la estructura de la norma, lo son por tener un supuesto carácter metafísico incompatible con el conocimiento posible revelado por su teoría del conocimiento. La extraña idea relativa a la reducción del conocimiento científico al conocimiento causal y al conocimiento positivo-normativo es por ello crucial en la comprensión y en la evaluación de la obra de Kelsen. Ella solo puede ser correctamente comprendida a la luz de su propio contexto de influencia y discusión, el neokantismo, y de la discusión metafísica de disolución metafísica que constituye lógicamente el punto inicial de la pretensión global de Kelsen. El objeto de la segunda parte de este artículo es mostrar esa influencia y la forma peculiar que su adaptación toma en la obra de Kelsen.

La filosofía del derecho de fines del siglo XIX y de principios del siglo XX, incluyendo la obra temprana de Kelsen, con particular énfasis en sus trabajos realizados entre su escrito de habilitación y el exilio, constituyen disciplinas influenciadas de forma considerable por el movimiento académico dominante de entonces, el neokantismo. ${ }^{42}$ No se trata, por supuesto, de que solo el neokantismo haya ejercido influencia en la filosofía del derecho de la época. En parte, el naturalismo y la resistencia a este generalmente observable en las discusiones de

\footnotetext{
42 Sobre la influencia del neokantismo en la obra temprana de Kelsen, véase solo HEIDEMANN (2005), pp. 17-19; y HEIDEMANN (1997), pp. 23. En la exposición de Heidemann, la obra temprana de Kelsen aparece dividida en dos fases: la primera se encuentra compuesta por los escritos aparecidos entre su habilitación, 1911, y 1915, mientras que la segunda tendría lugar desde entonces hasta el exilio. La distinción tiene por objeto dar cuenta de diferencias apreciables entre su escrito de habilitación y su obra posterior. Si bien esas diferencias son relevantes, sobre todo por cierta falta de consistencia reconocida por el propio Kelsen respecto de la primera edición de su escrito de habilitación, el espíritu es literalmente el mismo. Por ello, prefiero hablar simplemente de "obra temprana" para referirme a toda la fase marcadamente neokantiana de la obra de Kelsen antes de su exilio.
} 
Wilenmann - El camino de la teoría pura del derecho...

finales del siglo XIX y principios del siglo XX, no se reduce a un problema interno del neokantismo. En este contexto cultural, sin embargo, la influencia crucial ejercida sobre quienes pasaron a dominar la discusión en el mundo de habla alemana (por ejemplo Stammler, Bierling o Radbruch) fue el neokantismo. En Kelsen esto es particularmente claro: más allá del conocimiento que este tenía sobre movimientos paralelos como el Círculo de Viena, ${ }^{43}$ las obras de referencia (críticas o de soporte) en la discusión metodológica eran, en general, a miembros del neokantismo. Sin embargo, la relativa heterogeneidad que caracteriza no solo al neokantismo como movimiento académico, sino ante todo a su recepción en la discusión teórica sobre el derecho, hace que la calificación de Kelsen como neokantiano sin explicación de su sentido sea especialmente poco elocuente. Si a ello se le suma la lejanía cultural y temporal del neokantismo en nuestro contexto, la calificación neokantiana de Kelsen parece ser una simple asunción verificada solo en construcciones cuya estructura es explícitamente neokantiana (o incluso derechamente kantiana), como es ante todo la norma fundante básica. La comprensión del sentido en que la obra de Kelsen continúa (y rompe parcialmente) con el proyecto neokantiano solo puede ser efectuada revisando con alguna mayor detención su relación con las distintas corrientes de este.

\subsection{La lejanía de Kelsen frente a Marburgo y Baden}

a) Introducción: sobre el vínculo que la investigación kelseniana reciente ha intentado establecer entre las escuelas neokantianas y la obra de Kelsen.

En su presentación tradicional, es usual distinguir entre neokantismo de Marburgo y neokantismo sur-alemán (también llamado neokantismo de Baden, pese a que universidades fuera de esa región, como Estrasburgo, tuvieran una influencia crucial). La distinción se refiere, por cierto, en primer término a grupos académicos, es decir, es una distinción de individuos, pero tiene también pretensiones de dar cuenta de distintas formas de comprensión general del proyecto de reestructuración de la filosofía. Así, el neokantismo de Marburgo habría intentado, ante todo, desarrollar un programa de filosofía del conocimiento en cuanto teoría de la racionalidad científica. Con ello, su vínculo natural habría sido el empirismo de las ciencias naturales y la lógica matemática. Sin romper con la utilización de la epistemología como base de su filosofía, el neokantismo suralemán habría intentado, en cambio, dar cuenta de la lógica de reconstrucción del mundo más allá del cientificismo. Su objeto es precisamente reconstruir la lógica de la cultura, esto es, de aquello que solo es comprensible en relación con su

\footnotetext{
${ }^{43}$ La relación de Kelsen con el Círculo de Viena, por ejemplo, se deja resumir bien con la siguiente fórmula de Robert WALTER, "Der Positivismus der Reinen Rechtslehre", en Jabloner y Stadler (Ed.), Logischer Empirismus und Reine Rechtslehre, Viena, 2001, pp. 1-2: "Uno no puede decir que estos dos movimientos [el positivismo jurídico vienés en la forma de la teoría pura del derecho y el Círculo de Viena JW] no se conocían entre sí - los integrantes de ambas escuelas se conocían por lo demás entre sí y Félix Kaufmann formaba parte de ambos círculos-, pero no se desarrolló entre ambos ninguna relación filosófica relevante".
} 
sentido, con la valoración que se hace de fenómenos individuales, por oposición al puro estudio de la naturaleza, es decir, a la pura generalización de fenómenos asumidos sin valor individual, ${ }^{44}$ con lo que su particular herencia kantiana vendría dada antes por adaptaciones en la teoría de las categorías, esto es, en la oferta de una especie de tipología de métodos. ${ }^{45}$

En Alemania, es usual vincular la influencia del neokantismo sur-alemán a la filosofía del derecho en sentido estricto de dicho período y, en particular, a la influencia ejercida sobre el más influyente filósofo del derecho del siglo XX, Gustav Radbruch, por oposición a la teoría del derecho neokantiana, representada sobre todo por Hans Kelsen, cuya influencia vendría ante todo desde Marburgo. ${ }^{46}$ En lo que me interesa mostrar aquí, esta descripción -al igual que la descripción opuesta, a saber, que la influencia de Kelsen sería el neokantismo sur-alemán por oposición a Marburgo- ${ }^{47}$ es confusa. La obra de Kelsen es en su contenido igualmente cercana y lejana al neokantismo sur-alemán y a Marburgo que lo que su tradicional oposición con Radbruch hace suponer. ${ }^{48} \mathrm{La}$ forma en que es cercana y lejana a ambos, es decir, su contenido propiamente neokantiano y peculiaridad en el contexto del neokantismo, explica su teoría del conocimiento jurídico y con ello su proyecto general en la ciencia del derecho. Para comprender esto es importante en primer lugar mirar el aspecto negativo: el sentido en que las obsesiones de las dos grandes escuelas neokantianas se encuentran ausentes en Kelsen. La caracterización de su propia obsesión peculiar puede después ser percibida por oposición a esa cuestión negativa.

b) Kelsen frente a Marburgo y Baden

Más allá de la profusa utilización del método trascendental, ${ }^{49}$ la influencia más evidente de la filosofía neokantiana sobre Kelsen es la creencia general en la generación de la realidad con sentido por el sujeto y, a partir de ello, en la posibilidad de generación distinta de esa realidad dependiendo del principio de

\footnotetext{
44 Véase RiCKERT (1926), pp. 14 ss; 78-80.

${ }^{45}$ La expresión es de DrEIER (1990), p. 71.

46 Véanse las referencias en PAULSON (2002), p. 233, nota 42.

47 PAULSON (2002), pp. 233 ss., quien intenta demostrar que la verdadera influencia neokantiana de Kelsen es Windelband y Rickert.

48 Similar HeidemanN (2005), p. 18. Las referencias explícitas de Kelsen a la obra de distintos autores neokantianos están documentadas en DREIER (1990), p. 33, nota 40.

${ }^{49}$ En esto, la influencia de Marburgo es innegable, pero es casi casual. Después de la publicación de la primera edición de su escrito de habilitación, Kelsen habría sido advertido en una recensión de Ewald respecto de la cercanía de su concepción respecto de la Ética de la Voluntad Pura de Hermann Cohen y, con ello, de la posibilidad de usar el método de argumentación trascendental para la fundamentación de su propia teoría del derecho. Ese parece ser el origen de la famosa cita de Kelsen a Cohen en el prólogo a la segunda edición de los Hauptproblemen. Al respecto, véase HeidemanN (1997), pp. 46 ss. Como puede verse más abajo, más allá de la utilización del método trascendental en sí, el centro de interés de Cohen y el objeto de deducción trascendental (en su caso, de la ética) son completamente distintos a las preocupaciones de Kelsen.
} 
Wilenmann - El camino de la teoría pura del derecho...

sintetización en cuestión. Esta forma de comprensión neokantiana (y kantiana) del conocimiento se deja resumir así: el conocimiento, la experiencia, se encuentra constituido exclusivamente por la generación de juicios válidos. El objeto del conocimiento no es por ello directamente la materia (el mundo), sino que está constituido por juicios hechos a su respecto. La validez de los juicios depende de la correcta aplicación de principios sintéticos. Así, por ejemplo, en el conocimiento de la forma de organización de la materia, la aplicación del principio de causalidad constituye a la experiencia; conocimiento correcto sobre el mundo natural es aplicación correcta del principio de causalidad en la elaboración de juicios causales. ${ }^{50}$ La tesis de Kelsen a este respecto es que el juicio causal no eliminaría el universo posible de conocimiento, sino que la aplicación de un principio normativo -el principio de imputación- permitiría obtener conocimiento normativo, siempre que esa aplicación tenga lugar respecto del derecho positivo. Esa tesis es peculiar, pero depende de la tesis generalmente compartida por el neokantismo sobre la estructura del conocimiento.

Por supuesto, afirmada con esa generalidad, lo anterior constituye un tópico igualmente presente en ambas escuelas neokantianas: la obsesión neokantiana con la distinción categorial en la generación de conocimiento (en las formas de sintetizar la materia y generar sentido) no es más que la marca general del movimiento. Esto es, la mayor parte de las tesis de Kelsen que de ahí surgen, a saber, la generación de la distinción categórica entre ser y deber, el rechazo a toda forma de realismo jurídico, la crítica al naturalismo y, a partir de ello, la generación de un principio metodológico central de imputación, son todos tópicos que se dejan reconducir, en alguna medida, tanto a Marburgo como al neokantismo suralemán. Ello explica la dificultad en la calificación de Kelsen como cercano a la escuela de Marburgo o a la escuela sur-alemana. El trabajo metodológico de Kelsen en la fundamentación de estas tesis es igualmente poco elocuente a este respecto. Durante toda la fase inicial de su etapa neokantiana Kelsen simplemente tomó distintas citas de filósofos, no siempre congruentes entre sí, para intentar explicar una distinción categórica (ser y deber; posteriormente causalidad e imputación como correlato de esa distinción) que, precisamente por su carácter elemental, parecía resistirse a demostración completa. ${ }^{51}$ Precisamente por ello es que la distinción aparece en distintos momentos relacionada no solo con Kant, sino también con Cohen, ${ }^{52}$ Windelband,${ }^{53}$ Simmel ${ }^{54}$ Rickert, ${ }^{55}$ o Herbart, ${ }^{56}$ y que

\footnotetext{
50 Similar HEIDEMANN (2005), p. 18.

51 Similar HEIDEMANN (1997), pp. 24-26.

52 Véase KELSEN (1923), pp. XVII-XVIII. Pese al reenvío al pasaje en que Cohen tematiza la distinción entre ser y deber, el tratamiento aparentemente ontológico de Cohen resulta incompatible con la versión madura de Kelsen. En Kelsen, se trata antes de una especie de fundamentación epistemológica de la distinción radical entre ser y deber: correctamente considerado, "el dualismo fundamental" se encontraría "constituido por una diferenciación total en la dirección de mirada teórico-cognitiva" (KELSEN (1968b), p. 37). Precisamente por ello es que la cita a Cohen se enmarca antes en su explicación del tratamiento de las relaciones entre Estado y derecho y no directamente en el apartado que tematiza la distinción entre ser y deber, en el que Windelband y Simmel son sus referencias preferidas. Es decir, la coincidencia conceptual con
} 
algunos de ellos son, en otros momentos, criticados por Kelsen. En eso, Kelsen era ilustrativa y universalmente neokantiano: la postulación de una diferencia categorial entre ser y deber se deja reconducir a todas las formas de neokantismo y no es incompatible con ninguna de las fijaciones que separan a ambas escuelas.

Por supuesto, la oposición de Kelsen a la filosofía del derecho tomada del neokantismo sur-alemán, de la que parece derivarse su usual clasificación como cercano a Marburgo, tiene un origen bibliográfico y conceptual concreto. Uno de los artículos programáticos más relevantes de la primera etapa de la obra de Kelsen, "La ciencia del derecho como ciencia normativa o ciencia de la cultura", es esencialmente un escrito polémico contra Rickert, Lask y Radbruch. En lo esencial, es correcto señalar que hay incompatibilidad parcial entre el dualismo categórico y excluyente de Kelsen (esto es, ser y deber ser serían irreductibles entre sí, pero no existirían categorías más allá de esta distinción) y las asunciones metodológicas del neokantismo sur-alemán. La pretensión de exclusión de Kelsen es incompatible con la pretensión general inclusiva del neokantismo sur-alemán, mientras que el vínculo establecido por Rickert y Lask entre realidad y cultura (y por extensión: ciencias culturales y ciencias empíricas) es a su vez incompatible con la pretensión de la ausencia de posibilidad de reducción de las otras categorías a la categoría del ser, la que es radicalmente seguida en la teoría del derecho de Kelsen. Pese a ello, esas diferencias no implican en caso alguno que la obra de Kelsen pueda ser designada por descarte in toto como perteneciente a la otra parte de la herencia neokantiana, de la misma forma que, al contrario, su relativa falta de discusión con Marburgo den cuenta de participación en la filosofía neokantiana sur-alemana.

En el caso de Marburgo, la lejanía de Kelsen con las fijaciones que caracterizan a la escuela puede verse inmediatamente al observar las reflexiones sobre teoría del derecho del más importante miembro de la escuela, Hermann Cohen. En su monumental Ética de la Voluntad Pura el análisis trascendental del derecho es utilizado por Cohen de modo directamente inverso a la forma que puede observarse en Stammler, Bierling o Kelsen. Mientras en ellos el método transcendental cumple una función de demostración de la realidad de conceptos estructurales inmanentes al derecho, en Cohen el método transcendental es aplicado al derecho con una pretensión doble: asumida su eficacia en la ordenación del conocimiento (su racionalidad en la aplicación), esa eficacia es tomada para demostrar la realidad del derecho mismo, cuyas condiciones de posibilidad -la

Cohen puede encontrarse en la reducción del lenguaje del Estado al lenguaje del derecho. Sin desarrollar una teoría completa del Estado como Kelsen, ya en Cohen puede encontrarse la misma representación: "La teoría del Estado es necesariamente teoría del derecho del Estado. Sin importar qué otras disciplinas contribuyan a constituir el concepto del Estado, las ciencias jurídicas constituyen de forma indiscutible su fundamento metodológico" (COHEN (1904), p. 60).

53 Véase KELSEN (1923), pp. VI ss. y 1 ss.

${ }^{54}$ Ibid.

55 Véanse las referencias en PAULSON (2002), pp. 237-238.

${ }^{56}$ KeLSEN (1968b), pp. 37-38. 
Wilenmann - El camino de la teoría pura del derecho...

ética- son a su vez demostradas en un segundo paso trascendental. Esto es: la racionalidad de la ciencia del derecho es tomada mediatamente como objeto de demostración de la realidad de sus condiciones de posibilidad, de lo que sería deducible la realidad de la ética. Ya que el método trascendental implica pragmáticamente una inversión de las funciones "fundamento" y "objeto" -el objeto sirve como fundamento de deducción de sus condiciones de posibilidad, las que normalmente debieran ser en realidad llamadas "fundamentos"-, la ciencia del derecho aparece literalmente como fundamento de toda norma ética.

Esta llamativa conclusión es una consecuencia de las fijaciones del neokantismo de Marburgo. De acuerdo con esta, lo relevante de la filosofía de Kant sería la asunción de la idea de que la verdad de los conceptos depende de la racionalidad de sus aplicaciones. "Toda filosofía se encuentra entregada al factum de las ciencias. Esta dependencia del factum de las ciencias nos parece lo eterno en la filosofía de Kant." ${ }^{57}$ Las aplicaciones de las ciencias naturales, su capacidad de describir el mundo y permitir su manipulación, implicarían la racionalidad, y con ello la verdad de sus conceptos. Algo similar sucedería con la relación entre lógica y matemáticas. Las matemáticas solo serían posibles (comprensibles) bajo asunción de axiomas lógicos que pueden ser reducidos al concepto de "la lógica", con lo que la racionalidad de las matemáticas en su capacidad de producir resultados plausibles y consistentes demostraría, a su vez, la verdad de esos axiomas, es decir, la lógica encontraría al mismo tiempo su fundamento y su realidad en las matemáticas. ${ }^{58} \mathrm{La}$ misma relación tendría lugar, según Cohen, entre derecho (conformado por la ciencia del derecho) y ética: "Lo análogo a las matemáticas está constituido por la ciencia del derecho. Por ello, puede ser designada como la matemática de las ciencias del espíritu, y ante todo de la ética". ${ }^{59}$ Esto es, la idea de derecho solo sería comprensible bajo asunciones generales normativas, pero la realidad de esas asunciones vendría dada precisamente por la racionalidad del objeto dependiente de ese fundamento, a saber, la propia ciencia del derecho. Por ello, "la ética se deja designar como la lógica de las ciencias del espíritu", y y la ciencia del derecho como sus matemáticas.

La plausibilidad de la tesis de Cohen es irrelevante para lo que aquí interesa. ${ }^{61}$ Lo esencial es ver la completa disimilitud de su centro de interés, revelada por la tesis del fundamento de la ética en la ciencia jurídica, con aquellas de la teoría del derecho del siglo XX y, ante todo, de Kelsen. La peculiar expresión de optimismo racionalista universalista característica de Marburgo es completamente ajena al pesimismo formalista que subyace a Kelsen. Por ello, la forma de la utilización del argumento trascendental en la reconstrucción del

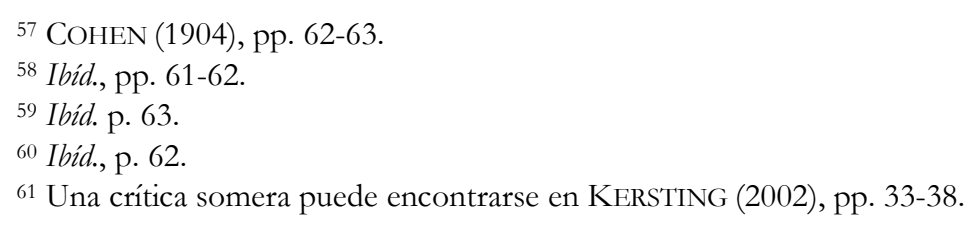


derecho por parte de Cohen fue explícitamente descartada por Kelsen durante su polémica con su discípulo Fritz Sander. ${ }^{62}$

Algo similar sucede con las fijaciones de Windelband y Rickert, no solo no compartidas por Kelsen, sino directamente criticadas por este. El proyecto de la escuela neokantiana sur-alemana se deja explicar sobre todo por la oposición entre ciencias naturales y ciencias culturales y, a partir de ello, por la pretensión de fundar valores absolutos que permitan dar fundamento a las ciencias culturales. Esto funciona en el nivel de las categorías de formación metodológica de la realidad. En la interpretación de Rickert, las categorías se dejan dividir en categorías constitutivas de la realidad (como, por ejemplo, la capacidad de reconocer extensión corporal de las cosas) y categorías de formación metodológica de la realidad, constitutivas de las ciencias. ${ }^{63}$ Por oposición a la observación y generalización sin valoración de la mirada causalista, las ciencias culturales se dejarían caracterizar a partir de relaciones de valor. Sus principios metodológicos en la interpretación de la realidad se relacionarían de esta forma con el concepto de valor. En la infinidad de eventos del pasado o de relaciones sociales, las disciplinas que constituyen las ciencias culturales -en este caso, la historia y la sociologíatendrían que proyectar valores generales para poder dar sentido y permitir la formación de conceptos válidos, es decir, para permitir el tratamiento científico de los datos en cuestión. Visto de forma simple: el historiador cuyas exposiciones se limiten a la reproducción de eventos pasados generalmente percibidos como "irrelevantes" precisamente no habría establecido relaciones con valores generales. ${ }^{64}$ Por supuesto, si valorar no significa más que expresar una actitud subjetiva propia frente al objeto analizado, el mero hecho de valorar puede difícilmente ser considerado como estándar de cientificidad. Por lo mismo, lo esencial en el sistema de Rickert es la identificación de valores existentes -correctamente dicho, en la misma nomenclatura que Kelsen utiliza para las normas, de valores válidos (gültig)-, cuya aplicación correcta en el conjunto de datos identificados permita tratamiento científico y el otorgamiento de un sentido válido a los datos analizados. Es decir, en las ciencias culturales se trata del establecimiento de relaciones con valores independientes y no, en cambio, de pura valoración (subjetiva). ${ }^{65}$ El proceso sintético de aplicación de ese valor general

\footnotetext{
${ }^{62}$ Véase KELSEN (1988), pp. 304-306. La crítica de Kelsen se limita en esto a señalar que los argumentos de Sander contra Cohen "son generalmente correctos". Sander había criticado la analogía entre ciencia del derecho y matemáticas de Cohen por asumir que la ciencia del derecho tendría una constitución analítica. En lo esencial, de la misma forma que la naturaleza se encuentra compuesta por el conjunto de juicios científicos sobre el material empírico enjuiciado, el derecho se encontraría compuesto por enunciados reconstruibles como juicios sintéticos aplicados por medio del proceso de conocimiento jurídico al material correspondiente (en Sander: a los "documentos jurídicos”). Véase SANDER (1988), pp. 204-208.

${ }^{63}$ RICKERT (1928), pp. 383 ss.

${ }^{64}$ El ejemplo es del propio RiCKERT (1926), p. 85.

${ }^{65}$ Sobre el concepto de relación de valor y su marcada distinción con el proceso de valorar, véase RICKERT (1926), pp. 84 ss. (en especial 87 ss.). La diferencia entre el concepto de valorar (bewerten) y
} 
Wilenmann - El camino de la teoría pura del derecho...

constituiría, por ello, al concepto que reclama validez. ${ }^{66}$ Como se trata de pura aplicación de valores existentes (válidos) con independencia de la actitud del científico, el proceso se dejaría describir como constatación objetiva por analogía con la constatación de relaciones causales que caracteriza a las ciencias naturales. ${ }^{67}$

En la generación de ciencia a partir de valores, el modelo de Windelband y Rickert encuentra su centro de interés y su dificultad crucial en el problema de la fundamentación. Si las ciencias culturas funcionan por aplicación de valores, solo puede hablarse de ciencia si los valores seleccionados para su aplicación admiten ser vistos como válidos. Lo específicamente neokantiano se deja sentir aquí: para permitir fundamentación de la validez de los valores, la existencia de una comprensión generalizada en el otorgamiento de valor a algo es asumido como expresión de un valor objetivamente válido (si se quiere: de un valor absoluto en s1). Si esto es expresión de una ontología metafísica plausible o no, es irrelevante para estos efectos. Lo crucial es que es incompatible con la teoría de la validez de Kelsen, la que precisamente, al fundarse en un objeto explícitamente asumido como inexistente -la norma fundante básica-, no necesita establecer relaciones de ese tipo. Al contrario: la etiqueta de "positivista" usualmente atribuida a Kelsen tiene valor expresivo sobre todo en la identificación de la posibilidad de superar las dificultades metafísicas en las teorías de la validez neokantianas a partir de la reducción de la teoría del derecho a pura teoría del derecho positivo. Esto precisamente no es el caso de la filosofía del derecho neokantiana sur-alemana: contra la pretensión de puro descubrimiento de estructuras inmanentes a un objeto contingente (el derecho positivo), su pretensión central es la generación de conocimiento general y absoluto del derecho por medio de la fundamentación de la validez de valores generales vinculables a este. Esto es ya visible claramente en Stammler, quien sin embargo reduce la "idea del derecho" a una simple idea regulativa y solo deja el "concepto (formal) del derecho" como estructura necesaria, pero se repite y radicaliza en las dos elaboraciones de filosofías del derecho desarrolladas en relación directa con la escuela neokantiana sur-alemana, a saber, las de Emil Lask y Gustav Radbruch. ${ }^{68}$

La teoría del derecho de Kelsen tiene una pretensión literalmente opuesta a la filosofía neokantiana sur-alemana. El problema del fundamento de la validez de las normas -si se quiere, el problema análogo al problema del fundamento de la validez de los valores aplicados por el científico cultural de Rickert- es literalmente eliminado por la teoría de la norma fundante básica de Kelsen. Por supuesto, a la

el de establecer relación de valor (wertbęiehen) es también resaltada por DREIER (1990), p. 72, nota 260, con ulteriores referencias.

${ }^{66}$ Véase, por referencia al tradicional ejemplo de la historia, RICKERT (1926), p. 81.

${ }^{67}$ Esa estrategia de demostración de cientificidad es completamente equivalente a la estrategia de Kelsen en relación con las ciencias jurídicas. Al igual que Rickert en relación con las ciencias culturales, la calificación "científica" es asegurada analíticamente por Kant por medio de la afirmación de la pura utilización de enunciados descriptivos por las ciencias jurídicas (véase $\operatorname{KELSEN}(1960)$, p. 78).

${ }^{68}$ En relación con Lask, véase solo DrEIER (1990), pp. 78-80. 
escuela neokantiana sur-alemana ello debe aparecer como una debilidad en la ontología de las normas de Kelsen. La postulación de una distinción categórica entre ser y deber como sustento central de su construcción, siendo el fundamento de lo segundo simplemente una asunción hipotética inexistente, parece revelar una debilidad teórica insoluble. La crítica supone, sin embargo, asumir que la distinción de Kelsen tiene sustento real, lo que precisamente, al menos en la fase madura de su obra temprana, no es el caso. ${ }^{69} \mathrm{Al}$ contrario: el reino de existencia de las normas, la validez, es el simple correlato de la aplicación de un principio sintético distinto, la imputación, a actos reales con puro sentido subjetivo. La norma no existe, de esta forma, como hecho, sino que es el sentido (uno podría decir: irreal) de hechos. En tanto pura aplicación, el deber es una producción del sujeto de la misma forma en que la representación de la realidad en cuanto naturaleza ordenada, por aplicación del principio de causalidad, lo es. La generación de ese paralelo es el más claro rasgo kantiano y neokantiano de Kelsen. ${ }^{70}$ La caída en la inverosimilitud metafísica al tratar la validez es el fruto, al contrario, de la asunción de un correlato objetivo (el valor absoluto de Rickert) como herencia kantiana.

Por supuesto, en el caso de Rickert, el postulado de que la puesta en relación con valores tiene su fundamento en la existencia de valores absolutos tenía por objeto permitir fundar el carácter científico de la historia, sociología y otras ciencias culturales. Si, en cambio, valorar constituyera pura prestación personal, entonces se trataría de operaciones esencialmente acientíficas. En la teoría del derecho, esa preocupación simplemente no resulta aplicable: el problema de la validez de las normas no es directamente un problema relacionado con la cientificidad de ciertos métodos. De la misma forma que la pretensión racionalista de Cohen es irreconocible en Kelsen, el problema de la generación de métodos racionales de entrega de sentido y, con ello, la pretensión de evitar un relativismo en la fundamentación de valores es, en el sentido que le interesa a Rickert, ajeno a este. Al contrario: Kelsen asume ese relativismo valórico al postular una teoría científica del derecho solo en cuanto teoría del derecho positivo. Considerar a Kelsen como un neokantiano de influencia sur-alemana, más allá de la influencia de ciertas formulaciones de Windelband o Rickert, es por ello completamente errado. En Kelsen no hay ni fe en el racionalismo excluyente de las ciencias y de sus aplicaciones, ni fe en el optimismo del pluralismo valórico sur-alemán.

\footnotetext{
${ }^{69}$ Las citas, por ejemplo, a Cohen y la distinción entre reino de la realidad y de la normatividad, postulada ya en su escrito de habilitación para explicar la diferencia entre ser y deber, pueden hacer pensar en la creencia en la existencia de una cierta ontología de la distinción por parte de Kelsen. Al mismo tiempo, la insistencia en la formulación de la teoría de la norma fundante básica en la completa falta de relación entre ser y deber también puede hacer pensar en que la expresión "dos reinos distintos", utilizada en la descripción de la oposición ser y deber, tiene sustento ontológico. Si esto es así o no es solo un problema menor. Es, en cambio, claro que la validez no es en sí expresiva de nada real; si existe diferencia ontológica entre validez y realidad, esa diferencia no implica el postulado de una segunda sustancia, sino solo la negación de la segunda (lo válido no es real). Al respecto, véase también HeIDEMANN (1997), p. 25; y PAUlSON (2005), pp. 206-210.

${ }^{70}$ Explícito en KELSEN (1968c), pp. 281 ss.
} 
Wilenmann - El camino de la teoría pura del derecho...

\subsection{El neokantismo agnóstico de Kelsen}

La comparación con la filosofía neokantiana, en particular con la filosofía neokantiana sur-alemana, permite reconocer en el neokantismo de Kelsen a un neokantismo agnóstico. La teoría del derecho de Kelsen es una pretensión de demostración de la realidad de los procesos de interpretación categórica no causal de la realidad pese a la eliminación de la creencia en distintas sustancias metafísicas ("distintas realidades"). ${ }^{71}$ La relación de Kelsen con el neokantismo admite así ser vista de forma equivalente a su relación con la tradición de discusión teórica del derecho: aunque los tópicos se mantienen, su obra pretende eliminar la metafísica ingenua o inverosímil contenida en parte de la tradición. La más clara expresión de ese agnosticismo se encuentra en la sumamente elocuente descripción programática contenida en el prólogo a la Teoría General del Estado: "Dualismo en ser y deber; reemplazo de postulados metafísicos e hipóstasis por categorías trascendentales como condiciones de la experiencia; transformación de contraposiciones absolutas, cualitativas y transistemáticas en el interior de una misma disciplina, en diferencias relativas, cuantitativas e intrasistemáticas; descenso de la esfera subjetiva del psicologismo y entrada al ámbito de la validez lógico-objetiva". ${ }^{72}$ Su radicalidad, y a partir de ello su magnitud para la teoría del derecho, se encuentra precisamente en la generación de una teoría del derecho completa pese a eliminar, al mismo tiempo, todas las asunciones metafísicas problemáticas, a saber, el naturalismo del positivismo tradicional y la ontología inverosímil de sus rivales. Visto así, el que la conceptualización del derecho en Kelsen resulte en completa pérdida de sustancia y en pura explicitación de su lógica interna y de las asunciones formales dadas por esa estructuración interna -la más acertada, pero no por ello decisiva, de las críticas tradicionales a la Teoría Pura del Derecho-, ${ }^{73}$ no puede ser visto sino como consecuencia lógica de su posicionamiento frente a su contexto.

Esto permite explicar la ciertamente más problemática de las asunciones metodológicas de Kelsen, pero a la vez el centro de su teoría del conocimiento jurídico, a saber, el reduccionismo dualista de su adaptación de la teoría de las categorías. Mientras la escuela sur-alemana postulaba un pluralismo indefinido - existen tantas distintas formas de otorgamiento de sentido válido como valores válidos puedan existir-, en Kelsen ser y deber (causalidad e imputación) son explícitamente asumidos como excluyentes de toda otra categoría. Que la interpretación de la realidad a partir de generalizaciones inductivas -la causalidadcuente como conocimiento objetivamente controlable y, con ello, científico, es algo que no puede sorprender a nadie, por más que ese mismo tipo de conocimiento científico resulte problemático. La actitud de la teoría del conocimiento frente a las ciencias naturales es exactamente la inversa que frente a otras disciplinas con pretensiones científicas: la demostración de racionalidad es,

\footnotetext{
${ }^{71}$ Esto es algo sobre lo que Kelsen insiste recurrentemente. Así ya en KELSEN (1968b), p. 38.

72 KeLsen (1925), p. VII.

${ }^{73}$ Sobre la crítica, véase solo, con numerosas referencias ulteriores, DREIER (1990), pp. 19-20.
} 
en general, simple y poco problemática, con lo que la crítica de su racionalidad tiene en general la carga de la prueba. Que ese mismo estatus solo sea postulable respecto del conocimiento jurídico es en cambio una tesis a primera vista extravagante. No solo no es probable que ante la pregunta por disciplinas no causales que admitan ser tratadas como científicas, las ciencias jurídicas ocupen el primer lugar, sino que el principio postulado por Kelsen como segundo principio sintético disponible en el conocimiento humano, el principio de imputación, no tiene ninguna historia que mostrar. La tesis de Kelsen, sin embargo, es que solo en la interpretación jurídica del mundo -en términos neokantianos: en la aplicación del principio de imputación respecto del conjunto de actos que permiten obtener conocimiento sobre la conformación normativa del mundo, el derecho positivopuede encontrarse un conjunto de convenciones cuya extensión sea igualmente amplia para asegurar comprensión objetiva común. El argumento a este respecto puede construirse por analogía con las ciencias naturales: el funcionamiento del derecho positivo, la mera asunción de su existencia, supone una conjunto de convenciones interpretativas comunes de la realidad -reducida por Kelsen al principio de imputación, que no es más que la estructura de la norma jurídica postulada por él- que hace posible la sintetización de forma equivalente a la constitución de la naturaleza (la realidad interpretada por medio del principio de causalidad). Esas asunciones existen porque el derecho funciona, por lo que el conocimiento jurídico puede ser tratado como científico.

El agnosticismo (bien podría decirse: positivismo) de Kelsen se revela aquí en toda su magnitud: en la creencia en que nuestra limitación en la interpretación común de la realidad a la interpretación causal solo es superada gracias al factum del derecho positivo, esto es, gracias al conjunto de convenciones reales que permiten la interpretación del mundo en relación con deberes asumidos como válidos. En esto no hay ninguna asunción especial respecto de una ontología particular del derecho que le permita postularse como objeto de conocimiento gracias a su sustancia, o respecto de una lógica particularmente consistente (al contrario, Kelsen criticaría la falta de lógica en las reconstrucciones alternativas del derecho) que garantice su conocimiento racional. En otras palabras: no es que el principio de imputación tenga una entidad particular; al contrario, el principio de imputación no es más que la estructura del derecho positivo mismo y su aplicación solo es científica cuando es aplicada a él. Por lo mismo, no se trata de que exista algo así como un principio a priori inserto en nuestro entendimiento; al contrario, nuestro entendimiento se encuentra conformado por la existencia del derecho positivo, cuya comprensión correcta supone la asunción de algo así como el principio de imputación. La estructura de esa relación es la estructura del principio de imputación.

Lo anterior es crucial en la difícil comprensión de las tesis de la teoría del conocimiento de Kelsen, por lo que merece ser explicado nuevamente. Al interpretar su tesis sobre la reducción de todo conocimiento científico no causal al conocimiento jurídico gracias al principio de imputación, es importante no confundirse con la semántica abstracta de Kelsen. Los conceptos abstractos de 
Wilenmann - El camino de la teoría pura del derecho...

deber e imputación no anteceden al derecho en su fundamentación, sino que son correlativos al derecho. Uno puede, por cierto, distinguir didácticamente entre objeto del conocimiento (derecho) y estructura del conocimiento (la imputación), pero ello no quiere decir que la existencia del objeto se funde en un principio estructural que le anteceda temporalmente. La tendencia, ya perceptible en el concepto kantiano de juicios sintéticos a priori, a hacer parecer que la distinción entre objeto y condición estructural tiene un correlato temporal, tiene que ser resistida. Al contrario: la estructura del conocimiento se ve definida por su objeto, de la misma forma en que el conocimiento del objeto presupone esa estructura. El principio de imputación no es más que la estructura de interpretación jurídica del mundo provista por el propio derecho. Precisamente por ello es que la tesis (anti)metafísica respecto del conocimiento del derecho presupone un compromiso con el derecho positivo, en este caso especialmente radical. Así, la tesis sobre la imposibilidad de conocimiento de cualquier norma no jurídica -el escepticismo ético de Kelsen-, es en realidad, otra parte de la tesis de la reducción del conocimiento no causal al conocimiento jurídico.

La insistencia sobre la cientificidad de la teoría del derecho habla categóricamente a favor de esta interpretación y permite, con ello, ver en la teoría de Kelsen una respuesta limitada al problema de Rickert, esto es, se trata de una demostración de que existen formas de interpretación conjunta del mundo más allá de las ciencias naturales y cuya corrección puede ser demostrada con suficiente abstracción de valoraciones personales para ser objeto de conocimiento.

Pese a la paulatina desaparición del horizonte de discusión continental y, ante todo, neokantiano que puede observarse en la obra de Kelsen posterior al exilio, incluyendo a la segunda edición de la Teoría Pura del Derecho, esta admite siempre ser vista como una pretensión de realización de aquello que solo se revela claramente al posicionar su obra en el contexto que le corresponde, a saber, de una determinación del tipo de conocimiento general que puede establecerse sobre el derecho. No solo su teoría del sistema jurídico y de las normas, en parte relevante derivadas directamente de su idea central sobre el conocimiento normativo, sino también otras construcciones contraintuitivas como la teoría del Estado o la teoría de la personalidad, pueden ser comprendidas como determinación del tipo de conocimiento normativo posible que puede establecerse sobre el objeto correspondiente a partir de las limitaciones que su principio de organización metodológica le impone. Pese a la radical pérdida de relevancia que esta forma de proceder implica para cuestiones cruciales como la teoría moral o la comprensión de la influencia de la política en el derecho, es precisamente ese compromiso radical con la comprensión interna del derecho el que hace que la obra de Kelsen siga siendo probablemente la mejor versión disponible de una teoría del derecho a la vez suficientemente verosímil y consciente de sus propias asunciones (es decir, no ingenua). 


\section{BIBLIOGRAFÍA}

* BIERLING, Ernst Rudolf (1979): Juristische Prinzipienlebre I (2. Edición, Aalen, Scientia Verlag) (reimpresión de la segunda edición publicada en Tubinga, 1894).

* BROCKMÖLLER, Annette (1997): Die Entstehung der Rechtstheorie im 19. Jahrbundert in Deutschland (Baden-Baden, Nomos).

* COHEN, Hermann (1904): System der Philosophie, Zweiter Teil, Ethik des reinen Willens (Berlín, Bruno Cassirer).

* DREIER, Horst (1990): Rechtslehre Staatssoziologie und Demokratietheorie bei Hans Kelsen (2. Edición, Baden-Baden, Nomos).

* DREIER, Ralf (1975): Was ist und wozu Allgemeine Rechtstheorie? (Tubinga, Mohr Siebeck).

* GÜNTHER, Klaus (2005): Schuld und kommunikative Freiheit (Fráncfort del Meno, Vittorio Klostermann).

* HEIDEMANN, Carsten (1997): Die Norm als Tatsache. Zur Normentheorie Hans Kelsens (1. Edición, Baden-Baden, Nomos).

(2005) "Der Begriff der Zurechnung bei Hans Kelsen”, en Paulson/Stolleis (eds.), Hans Kelsen (Tubinga, Mohr Siebeck), pp. 17-34.

* HUgO, Gustav: (1823) Lebrbuch der juristischen Enzyklopädie (7. Edición, Berlín, Mylius).

* KELSEN, Hans (1923): Hauptprobleme der Staatsrechtslehre (2. Edición, Tubinga, Mohr). (1968a): "Zur Theorie der juristischen Fiktionen" (1919), en Klecatsky/Marcic/Schambeck, Die Wiener Rechtstheoretische Schule (Tomo II, Viena, EuropaVerlag), p. 1215-1241.

(1968b): "Die Rechtswissenschaft als Norm- oder Kulturwissenschaft" (1916), en Klecatsky/Marcic/Schambeck, Die Wiener Rechtstheoretische Schule (Tomo I, Viena, EuropaVerlag), p. 37-93.

(1988): "Rechtswissenschaft und Recht" (1922), en Paulson, Stanley (Ed.), Die Rolle des Neukantianismus in der Reinen Rechtslehre (Aalen, Scientia Verlag), pp. 279-411. (1925): Allgemeine Staatslehre (Berlín, Springer).

(1968c): "Die philosophischen Grundlagen der Naturrechtslehre und des Rechtspositivismus", en Klecatsky/Marcic/Schambeck, Die Wiener Rechtstheoretische Schule (Tomo I, Viena, Europa-Verlag), pp. 281-350.

(1960): Reine Rechtslebre (2. Edición, Viena, 1960, Österreichische Staatsdruckerei) (reimpresión 1992).

* KERSTING, Wolfgang (2002): "Neukantianische Rechtsbegründung”, en Alexy/ Meyer/ Paulson/ Sprenger (eds.), Neukantianismus und Rechtsphilosophie (Baden-Baden, Nomos), pp. 23-68.

* MERKEL, Adolf (1899): Gesammelte Abhandlungen aus dem Gebiet der allgemeinen Rechtslehre und des Strafrechts (Estrasburgo, Trübner).

* MÖLLERS, Christoph (2008): Der vermisste Leviathan (Fráncfort del Meno, Suhrkamp).

* NEUMANN, Ulfrid (2005) "Wissenschaftstheorie der Rechtswissenschaft bei Hans Kelsen und Gustav Radbruch", en Paulson/Stolleis (eds.), Hans Kelsen (Tubinga, Mohr Siebeck), pp. 35-55.

* PAULSON, Stanley (1990): "Läßt sich die Reine Rechtslehre transzendental begründen?” en Rechtstheorie, pp. 155-179.

(2002): "Faktum/Wert-Distinktion - Kelsen als Neukantianer", en Alexy/ Meyer/ Paulson/ Sprenger (eds.), Neukantianismus und Rechtsphilosophie (Baden-Baden, Nomos), pp. 223-251.

(2005): "Zwei radikale Objektivierungsprogramme in der Rechtslehre Hans Kelsens", en Paulson y Stolleis (eds.), Hans Kelsen (Tubinga, Mohr Siebeck), pp. 191-220

* RICKERT, Heinrich (1926): Kulturwissenschaft und Naturwissenschaft (7. Edición, Tubinga, Mohr). 
Wilenmann - El camino de la teoría pura del derecho...

(1928): Der Gegenstand der Erkenntnis (6. Edición, Tubinga. Mohr).

* SANDER, Fritz (1988): "Rechtsdogmatik oder Theorie der Rechtserfahrung?" (1921), en Paulson, Stanley (Ed.), Die Rolle des Neukantianismus in der Reinen Recbtslebre (Aalen, Scientia Verlag), pp. 115-278.

* STAMMLER, Rudolf (1925): Rechtsphilosophische Abhandlungen und Vorträge. Erster Band (Charlottenburg, 1925) (Reimpresión Aalen, Scientia Verlag, 1970).

* von der PFORDTEN, Dietmar (2001): Rechtsethik (Múnich, Beck).

* WALTER, Robert (2001): "Der Positivismus der Reinen Rechtslehre", en Jabloner y Stadler (Ed.), Logischer Empirismus und Reine Rechtslehre (Viena, Springer), pp 1-18.

* ZIEMANN, Sascha (2009): Neukantianisches Strafrechtsdenken (Baden-Baden, Nomos). 